\title{
Article \\ The Effect of Recycled HDPE Plastic Additions on Concrete Performance
}

\author{
Tamrin ${ }^{1, *}$ and Juli Nurdiana ${ }^{1,2}$ (D) \\ 1 Faculty of Engineering, Mulawarman University, Samarinda 75117, Indonesia; j.nurdiana@utwente.nl \\ 2 Department of Governance and Technology for Sustainability, University of Twente, \\ 7522 NB Enschede, The Netherlands \\ * Correspondence: fts_tamrin@ft.unmul.ac.id
}

check for

updates

Citation: Tamrin; Nurdiana, J. The Effect of Recycled HDPE Plastic

Additions on Concrete Performance. Recycling 2021, 6, 18. https:// doi.org/10.3390/recycling6010018

Received: 17 October 2020

Accepted: 3 March 2021

Published: 6 March 2021

Publisher's Note: MDPI stays neutral with regard to jurisdictional claims in published maps and institutional affiliations.

Copyright: (c) 2021 by the authors. Licensee MDPI, Basel, Switzerland. This article is an open access article distributed under the terms and conditions of the Creative Commons Attribution (CC BY) license (https:// creativecommons.org/licenses/by/ $4.0 /)$.

\begin{abstract}
This study examined HDPE (high-density polyethylene) plastic waste as an added material for concrete mixtures. The selection of HDPE was based on its increased strength, hardness, and resistance to high temperatures compared with other plastics. It focused on how HDPE plastic can be used as an additive in concrete to increase its tensile strength and compressive strength. 156 specimens were used to identify the effect of adding different percentages and sizes of HDPE lamellar particles to lower, medium, and higher strength concrete for non-structural applications. HDPE $0.5 \mathrm{~mm}$ thick lamellar particles with sizes of $10 \times 10 \mathrm{~mm}, 5 \times 20 \mathrm{~mm}$, and $2.5 \times 40 \mathrm{~mm}$ were added at $2.5 \%, 5 \%, 10 \%$, and $20 \%$ by weight of cement. The results showed that the medium concrete class (with compressive strength equal to $10 \mathrm{MPa}$ ) had the best response to the addition of HDPE. The 5\% HDPE addition represented the optimal mix for all concrete types, while the $5 \times 20 \mathrm{~mm}$ size was best.
\end{abstract}

Keywords: concrete additive; concrete mixture; plastic waste; HDPE; plastic lamellar particles

\section{Introduction}

Plastic has long been considered a manmade material with many benefits. It has lightweight properties and is easily shaped to the designer's desires. Its versatile properties have led to its widespread use. Since 2016-2017, plastic consumption has increased from 335 million tons to 348 million tons. This demand is expected to reach 485 million tons by 2030 [1]. The downside of plastic use is the waste generated and the environmental pollution caused because many plastics are not biodegradable and can take between 500 and 1000 years to decompose [2]. The pollution risks from the toxins released can impact groundwater quality, animal/human health, food-chain poisoning, and reduction in soil fertility [3]. Furthermore, if burnt in an open space, plastics produce carbon monoxide (a greenhouse gas). If disposed of in waterways, plastics can cause siltation and impede water flows, thereby creating a flood risk [4,5]. Research on beaches has shown that coastline plastic waste in 192 countries in 2010 amounted to between 4.8 and 12.7 million metric tons [6]. This waste threatens marine organisms [7] and has led to many demands to restrict plastic use and reshape behavior at the consumer level [8]. Recycling has increased in developed countries since 2006 [1] and offers a partial solution. The regular process of plastic recycling starts with sorting it into several polymer types, followed by cleaning, scraping, smelting, and converting it into pellets to be repurposed into plastic bags, plastic containers, carpets, jacket insulation, and other materials. However, traditional recycling suffers from cross-contamination and requires high energy consumption [9]. In 2018, processing plastic waste for energy used $43 \%$ of all of the collected post-consumer waste stream [1]. Furthermore, the insufficient processing and management of plastic waste worldwide face the challenge of insufficient plastic waste treatment facilities at all stages of collection, separation, and disposal. By 2050, it is projected that about 12 billion metric tons of plastic litter will end up in landfills and the natural environment [10]. Many countries, 
including Indonesia, experience problems with plastic waste. Indonesia generates some 67.8 million tons of waste, with plastic waste being the second-largest waste stream after organic waste, reaching $17 \%$ in 2018 [11]. To solve the problems of plastic waste and divert this away from landfill, requires any opportunities to be identified within the value chains.

Investing in a circular system to manage plastic pollution offers potential solutions with social and environmental benefits. Circularity will retain the value of plastic materials if they are returned back into the supply chain, thus reducing the volume of discarded plastics ending up in nature. Therefore, the identification of a relevant local strategy for waste (including plastics) and the tailoring of partnerships to suit various stakeholders (i.e., businesses, industries, and civil society) are necessary $[12,13]$. Here, building a nexus between the waste and construction sectors emerges as a possible option for increasing plastic circularity, especially macro-plastics, which are in widespread use [14]. The additional value to be obtained from their use as an additive in concrete mixtures could also create new business opportunities [15]. The final application from plastic additions to concrete, as examined in this study is expected to be for non-structural projects, such as wall panels, parking lots, or paths [16-18]. Even plastic fibers can be used below the concrete layer in constructing rigid pavements.

Concrete has properties that are sensitive to the type of added materials that are beyond those specified in the traditional job mix design. The strength of concrete depends on the type and size of the aggregates used [19-21], and different additive materials produce variations in tensile strength and compressive strength [22-25]. Single-use plastics are considered suitable for disposal as admixtures in concrete, as low-carbon reusable materials, e.g., PET (polyethylene terephthalate) [26] and HDPE (high-density polyethylene) [27]. The advantages of using plastic additions in concrete are that they are lightweight, better resistant to weather, waterproof [28], and confer thermal insulation properties $[9,29]$. However, compared to PET, HDPE has higher temperature resistance than PET (melting at $130-135{ }^{\circ} \mathrm{C}$ ). Further, as Merli et al. [30] identified, HDPE is less discussed in the literature compared to PET. This motivated our interest and focus on HDPE.

A few researchers have discussed the use of HDPE in concrete in different contexts. For instance, Pesic et al. [31] investigated the effect recycled HDPE fibers had for reinforced concrete for structural uses using two different fiber diameters $(0.25 \mathrm{~mm}$ and $0.4 \mathrm{~mm})$ with $0.40 \%, 0.75 \%$, and $1.25 \%$ fiber volume fraction. The study showed that the HDPE fiber reinforced concrete of $0.75-1.25 \%$ could maintain a constant post-cracking tensile of $30-40 \%$ of the flexural peak capacity. The use of HDPE for non-structural uses was discussed by Lopez et al. [32], who considered using recycled HDPE as a partial replacement of coarse aggregate in mixes of Acrylic Polymer Pervious Concrete (AcPPC) at ratios of 10\%, 20\%, and $30 \%$ at sizes of $\frac{1}{2}$ " and $\frac{3}{4}$. The study showed that the optimum strength was reached by a $10 \%$ addition at sizes of $\frac{1}{2}$ ". Further, by using a different type of plastic, Jain et al. [16] investigated the effect of plastic bag additions to concrete at $0.5,1,2,3$, and $5 \%$ of the weight of concrete. They found that a higher percentage of plastic reduced concrete's workability. The addition also affected the bonding between plastic aggregate and cement paste, as it created voids, thus reducing the concrete strength. The above-mentioned studies clearly emphasized that plastic addition could benefit concrete properties at certain levels, and contribute to sustainable construction. However, how different types of plastics may affect the behavior of concrete is an interesting issue, which offers scope for discussion and development.

Unlike these previous studies, we have investigated different aspects. Our study examines the potential use of HDPE addition on different concrete classes. We assess the effect of various HDPE lamellar particle sizes and percentages as lightweight admixtures into different concrete mixes used for non-structural works, but not as a replacement to cement or other materials. This paper is structured as follows: Section 1 is an introduction providing the background and aim of this study. It is followed by a description of materials and methods in Section 2. The results of the tests are provided in Section 3 and discussed in Section 4. Conclusions and recommendations for future research are presented in Section 5. 


\section{Materials and Methods}

This study used concrete mixes formed from cement and aggregate (fine and coarse aggregate). These are designed to fall into three concrete classes: lower, medium, and higher concrete strength. Lower concrete strength is in the following named as B0 and it represents concrete with cylindrical strength of $\mathrm{f}^{\prime} \mathrm{c}=7 \mathrm{MPa}$. Medium and high concrete strength here refers to cylindrical strength $\mathrm{f}^{\prime} \mathrm{c}$ equal to $10 \mathrm{MPa}$ and $25 \mathrm{MPa}$ respectively. Three different sizes of HDPE lamellar $(10 \times 10 \mathrm{~mm}, 5 \times 20 \mathrm{~mm}$, and $2.5 \times 40 \mathrm{~mm})$ with the same thickness of $0.5 \mathrm{~mm}$ were added to the mixtures to examine their effect on concrete properties. The ACI (American Concrete Institute) and ASTM (American Society for Testing and Materials) testing standards were used to calculate specific gravity, slump value, unit weight, tensile and compressive strength. Table 1 provides a summary of the standard testing used in this research.

Table 1. The standards used for concrete testing.

\begin{tabular}{ll}
\hline Standard & Targeted Testing \\
\hline ASTM C-127 & Specific gravity of coarse aggregate \\
\hline ASTM C33-99a & $\begin{array}{l}\text { Adequate grading requirement and aggregate } \\
\text { quality; sieve analysis }\end{array}$ \\
\hline ASTM C29/C29M-07 & Unit weight for fine and coarse aggregate \\
\hline ASTM C131/C131M-20 & $\begin{array}{l}\text { Resistance to degradation by abrasion on } \\
\text { small-size coarse aggregate }\end{array}$ \\
\hline ACI 211.1-91 & $\begin{array}{l}\text { Standard Practice for Selecting Proportions for } \\
\text { Normal, Heavyweight, and Mass Concrete }\end{array}$ \\
\hline ASTM C143 & Slump test \\
\hline ASTM C39 & Compressive strength \\
\hline ASTM C496 & Tensile strength \\
\hline
\end{tabular}

\subsection{Materials}

\subsubsection{Cement}

As this study's scope involved non-structural applications, the examination used cement type 1, which is intended for walls, pavement, sidewalks, and other precast products. Using the ASTM C-127 standard, this cement material was found to have a specific gravity of $3.18 \mathrm{~g} / \mathrm{cm}^{3}$, which falls in the acceptable range of $3.1-3.3 \mathrm{~g} / \mathrm{cm}^{3}$. This cement composition comprises four main chemical compounds, i.e., tricalcium silicate $\left(3 \mathrm{CaO} \cdot \mathrm{SiO}_{2}\right)$, shortened to $\mathrm{C}_{3} \mathrm{~S}(55 \mathrm{wt} . \%)$, dicalcium silicate $\left(2 \mathrm{CaO} \cdot \mathrm{SiO}_{2}\right)$, abbreviated to $\mathrm{C}_{2} \mathrm{~S}(17 \mathrm{wt} . \%)$, tricalcium aluminate $\left(3 \mathrm{CaO} \cdot \mathrm{Al}_{2} \mathrm{O}_{3}\right)$, shortened to $\mathrm{C}_{3} \mathrm{~A}(10 \mathrm{wt} . \%)$, tetracalcium aluminoferrite $\left(4 \mathrm{CaO} \cdot \mathrm{Al}_{2} \mathrm{O}_{3} \cdot \mathrm{Fe}_{2} \mathrm{O}_{3}\right)$, shortened to $\mathrm{C}_{4} \mathrm{AF}(7 \mathrm{wt} . \%)$, carbon disulphide $\left(\mathrm{CS}_{2}\right)(6 \mathrm{wt} . \%)$. In addition, there are small amounts of minor compounds, e.g., alkali $\left(\mathrm{Na}_{2} \mathrm{O}\right)$, free calcium oxide (free $\mathrm{CaO}$ ), ignition loss, and magnesium oxide $(\mathrm{MgO})$ of which, according to Indonesian national standard (SNI No 15-2049/2015), the maximal amount should be less than 5 and $6 \mathrm{wt} . \%$ respectively.

\subsubsection{The Aggregates}

The aggregates refer to any particulates used as an inert filler in concrete. These vary from sand, gravel, crushed stone to blast-furnace slag. Following ASTM C33, the aggregates are categorized into fine and coarse aggregate. This study used sand as a fine aggregate within a range of $0.1-10 \mathrm{~mm}$ (Figure 1a), and crushed stone as a coarse aggregate meeting the range of 2-30 mm (Figure 1b). These aggregates were collected from Palu, Central Sulawesi, Indonesia. Palu's aggregates are considered basalt and are widely used for lightweight building walls and concrete in Indonesia. Its physical characteristics and 
quality provided adequate consolidation in concrete mixes, and offers higher resistance to alkali-silica reaction, compared to other aggregates obtained from areas in East Kalimantan.

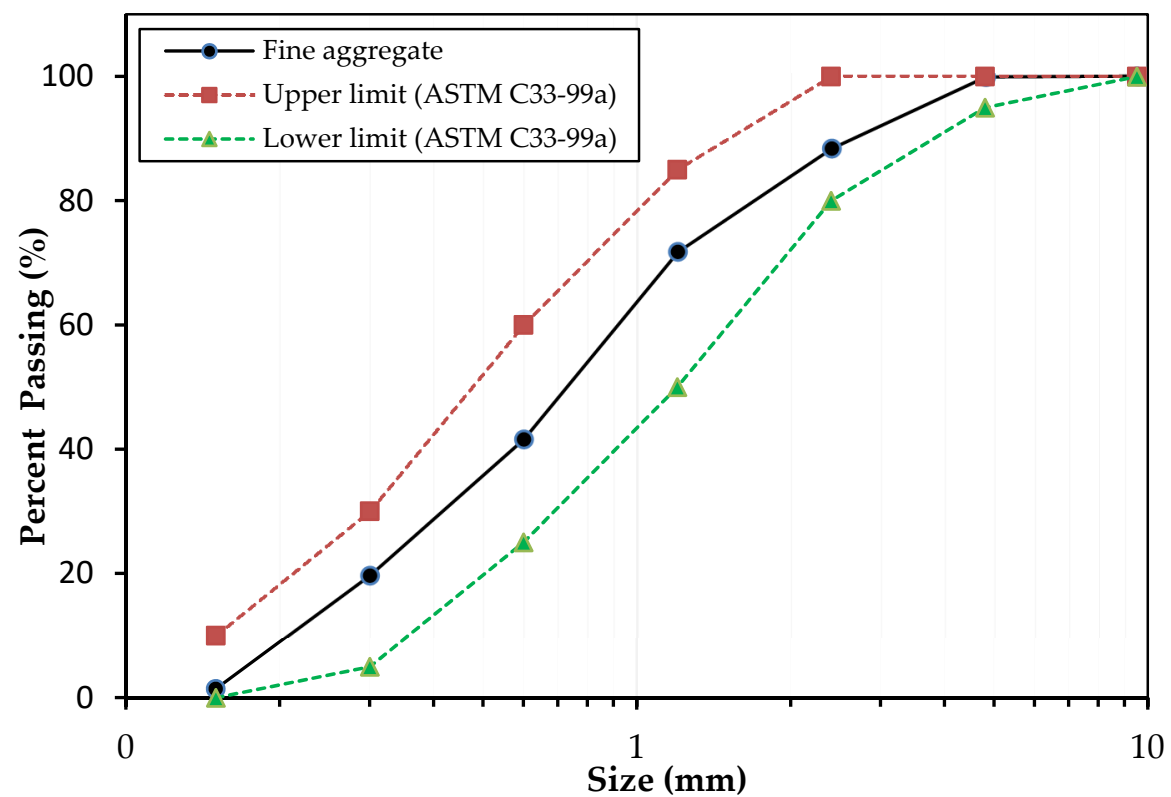

(a)

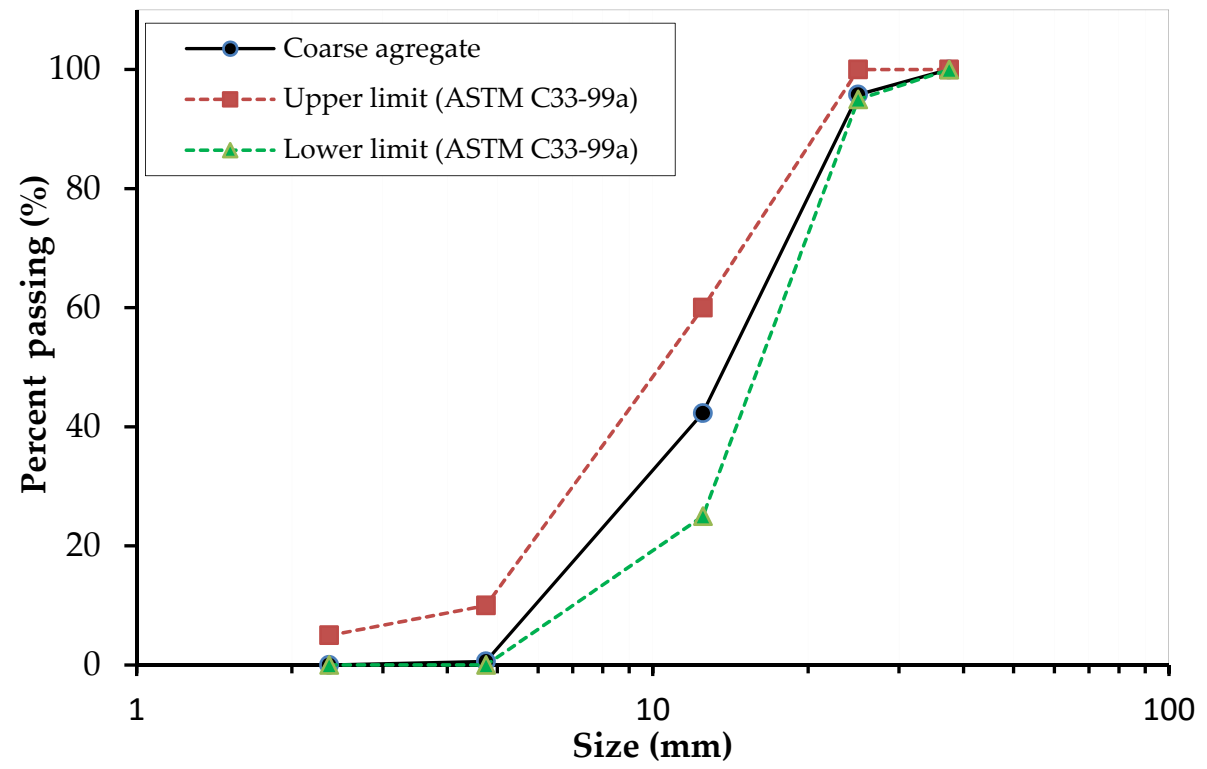

(b)

Figure 1. Aggregate size: (a) fine aggregate; (b) coarse aggregate.

These aggregates were tested at the Faculty of Engineering Laboratory, Mulawarman University, Samarinda, following the ASTM C33-99a standard [33] for sieve analysis, which defines the adequate grading requirement and aggregate quality in concrete. The results of this test for fine and coarse aggregate are shown in Figure 1.

The unit weight testing of fine and coarse aggregates was conducted using the ASTM C29/C29M-07 standard [34]. $2.55 \mathrm{~g} / \mathrm{cm}^{3}$ for the coarse aggregate and $2.54 \mathrm{~g} / \mathrm{cm}^{3}$ for the fine aggregate was obtained, meeting the standard requirement of $2.5-2.7 \mathrm{~g} / \mathrm{cm}^{3}$. The test for coarse aggregate abrasion was conducted using the ASTM C131/C131M-20 standard [35] and a result of $23 \%$ was obtained. This value was lower than the $27 \%$ ASTM limit. Table 2 provides the detailed physical properties of the materials used for mixing concrete. 
Table 2. Physical properties of cement and aggregates.

\begin{tabular}{|c|c|c|c|}
\hline Materials & Properties & Value & Allowable Range \\
\hline Cement type 1 & Specific gravity & $3.18 \mathrm{~g} / \mathrm{cm}^{3}$ & $3.1-3.3 \mathrm{~g} / \mathrm{cm}^{3}$ \\
\hline \multirow[t]{2}{*}{ Fine Aggregate } & Sieve size & Figure 1a & $\begin{array}{c}\text { Following ASTM } \\
\text { C33-99a }\end{array}$ \\
\hline & Unit weight & $2.54 \mathrm{~g} / \mathrm{cm}^{3}$ & $2.5-2.7 \mathrm{~g} / \mathrm{cm}^{3}$ \\
\hline \multirow[t]{3}{*}{ Coarse Aggregate } & Sieve size & Figure $1 \mathrm{~b}$ & $\begin{array}{c}\text { Following ASTM } \\
\text { C33-99a }\end{array}$ \\
\hline & Unit weight & $2.55 \mathrm{~g} / \mathrm{cm}^{3}$ & $2.5-2.7 \mathrm{~g} / \mathrm{cm}^{3}$ \\
\hline & Resistance to abrasion & $23 \%$ & Maximum of $27 \%$ \\
\hline
\end{tabular}

\subsubsection{Specimen Preparation of HDPE Lamellar Particles}

The HDPE plastic materials were collected from wastes disposed of in Samarinda landfills to reflect potential future plans to reduce non-sustainable waste that contaminate waterways and aquifers. They were rinsed in preparation for the cutting process. Figure $2 \mathrm{a}$ shows the production of lamellar particles and how we ensured a similar thickness for all the sheets. We implemented a cutting procedure using markings determined as a function of the pattern and size. First, a selection of HDPE plastic samples $0.5 \mathrm{~mm}$ thick was cut into lamellar particles before adding to the concrete mixture, excluding any thicker or less than $0.5 \mathrm{~mm}$. This process produced three sizes, namely, $10 \times 10 \mathrm{~mm}, 5 \times 20 \mathrm{~mm}$, and $2.5 \times 40 \mathrm{~mm}$; each with an identical surface area of $1 \mathrm{~cm}^{2}$. This ensures commonality of interaction between the plastic addition and cement in any change in propertie00s of concrete mixture and the bonding effect. Figure $2 b$ shows an example of HDPE lamellar particles with a size of $10 \times 10 \mathrm{~mm}$ at a similar thickness of $0.5 \mathrm{~mm}$ after the cutting process.

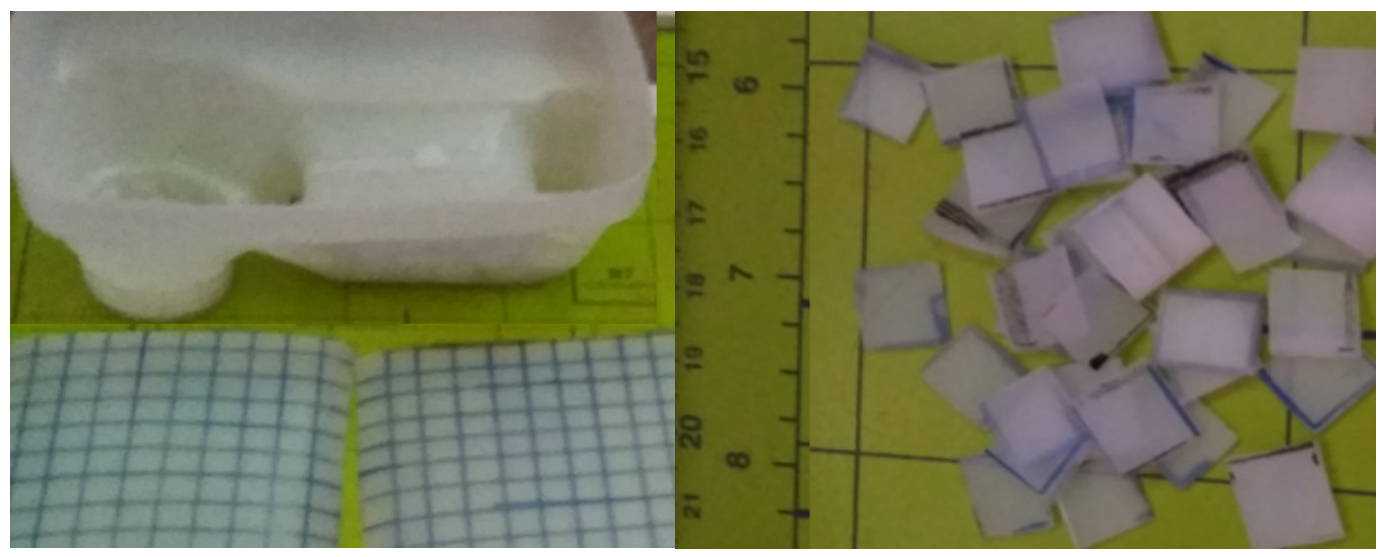

(a)

(b)

Figure 2. The preparation of high-density polyethylene (HDPE) addition: (a) marking procedure for the cutting process; (b) examples of HDPE lamellar particles with a size of $10 \times 10 \mathrm{~mm}$.

\subsection{Concrete Preparation and Testing}

\subsubsection{Job Mix Design}

The concrete mix design and the material composition of the three concrete types are shown in Table 3. The process of identifying the right proportion of concrete mixture complied with the standard practice for selecting proportions for normal, heavyweight, and mass concrete (ACI 211.1-91) [36]. Therefore, concrete strength tests were performed 28 days after casting to ensure that the resultant properties satisfied quality control designs. The concrete specimens were demolded after $24 \mathrm{~h}$ and kept in a water curing tank until the age of testing at a room temperature of $27^{\circ} \mathrm{C}$. We defined the slump value of the 
mixture for the three different concrete classes at the same range so it met cost efficiency and workability in the field. To meet this value, we set the $w / c$ ratio at different levels, according to the water to cement ratio used.

Table 3. Concrete job mix design.

\begin{tabular}{cccc}
\hline Description & B0 & $\mathbf{f}^{\prime} \mathbf{c 1 0}$ & $\mathbf{f}^{\prime} \mathbf{c} \mathbf{2 5}$ \\
\hline $\begin{array}{c}\text { Targeted average compressive } \\
\text { strength of the concrete }\end{array}$ & $7 \mathrm{MPa}$ & $10 \mathrm{MPa}$ & $25 \mathrm{MPa}$ \\
Water to cement ratio & 0.95 & 0.63 & 0.52 \\
Slump value & $120 \pm 5 \mathrm{~mm}$ & $120 \pm 5 \mathrm{~mm}$ & $120 \pm 5 \mathrm{~mm}$ \\
Amount of water & $180 \mathrm{~kg} / \mathrm{m}^{3}$ & $190 \mathrm{~kg} / \mathrm{m}^{3}$ & $215 \mathrm{~kg} / \mathrm{m}^{3}$ \\
Amount of cement & $190 \mathrm{~kg} / \mathrm{m}^{3}$ & $295 \mathrm{~kg} / \mathrm{m}^{3}$ & $413 \mathrm{~kg} / \mathrm{m}^{3}$ \\
Fine aggregate content & $969 \mathrm{~kg} / \mathrm{m}^{3}$ & $828 \mathrm{~kg} / \mathrm{m}^{3}$ & $687 \mathrm{~kg} / \mathrm{m}^{3}$ \\
Coarse aggregate content & $1010 \mathrm{~kg} / \mathrm{m}^{3}$ & $1014 \mathrm{~kg} / \mathrm{m}^{3}$ & $1220 \mathrm{~kg} / \mathrm{m}^{3}$ \\
\hline
\end{tabular}

\subsubsection{Mixing Process}

Table 4 shows the design experiments for the three concrete types, four different percentages of HDPE additions, lamellar particle sizes, and various aggregate particles used for the mixtures as described in Figure 1. The process started by mixing the different cement types and aggregates under dry conditions for a few minutes before adding water. The lamellar particles were then added to each concrete type according to their size categories $(10 \times 10 \mathrm{~mm} ; 5 \times 20 \mathrm{~mm} ; 2.5 \times 40 \mathrm{~mm})$ until the concrete mixture became homogeneous.

Table 4. Design experiment of specimens used.

\begin{tabular}{|c|c|c|c|c|c|c|c|c|}
\hline \multirow{2}{*}{$\begin{array}{c}\text { HDPE } \\
\text { Addition }\end{array}$} & \multirow{2}{*}{$\begin{array}{c}\text { Volume of } \\
\text { Concrete } \\
\left(\mathrm{m}^{3}\right)\end{array}$} & \multirow[b]{2}{*}{ Cement (kg) } & \multirow{2}{*}{$\begin{array}{c}\text { Fine } \\
\text { Aggregate } \\
\text { (kg) }\end{array}$} & \multirow{2}{*}{$\begin{array}{c}\text { Coarse } \\
\text { Aggregate } \\
\text { (kg) }\end{array}$} & \multirow[b]{2}{*}{$\begin{array}{l}\text { Water } \\
(\mathrm{kg})\end{array}$} & \multirow{2}{*}{$\begin{array}{c}\text { HDPE } \\
\text { Lamellar } \\
(\mathbf{k g})\end{array}$} & \multicolumn{2}{|c|}{ Number of Specimens } \\
\hline & & & & & & & $\begin{array}{l}\text { Compressive } \\
\text { Strength }\end{array}$ & $\begin{array}{l}\text { Tensile } \\
\text { Strength }\end{array}$ \\
\hline B0 & 0.021 & 4.03 & 20.54 & 21.41 & 3.82 & 0 & 2 & 2 \\
\hline \multicolumn{9}{|l|}{ B0-HDPE $2.5 \%$} \\
\hline $10 \times 10 \mathrm{~mm}$ & 0.021 & 4.03 & 20.54 & 21.41 & 3.82 & 0.10 & 2 & 2 \\
\hline $5 \times 20 \mathrm{~mm}$ & 0.021 & 4.03 & 20.54 & 21.41 & 3.82 & 0.10 & 2 & 2 \\
\hline $2.5 \times 40 \mathrm{~mm}$ & 0.021 & 4.03 & 20.54 & 21.41 & 3.82 & 0.10 & 2 & 2 \\
\hline \multicolumn{9}{|l|}{ B0-HDPE 5\% } \\
\hline $10 \times 10 \mathrm{~mm}$ & 0.021 & 4.03 & 20.54 & 21.41 & 3.82 & 0.20 & 2 & 2 \\
\hline $5 \times 20 \mathrm{~mm}$ & 0.021 & 4.03 & 20.54 & 21.41 & 3.82 & 0.20 & 2 & 2 \\
\hline $2.5 \times 40 \mathrm{~mm}$ & 0.021 & 4.03 & 20.54 & 21.41 & 3.82 & 0.20 & 2 & 2 \\
\hline \multicolumn{9}{|l|}{ B0-HDPE $10 \%$} \\
\hline $10 \times 10 \mathrm{~mm}$ & 0.021 & 4.03 & 20.54 & 21.41 & 3.82 & 0.40 & 2 & 2 \\
\hline $5 \times 20 \mathrm{~mm}$ & 0.021 & 4.03 & 20.54 & 21.41 & 3.82 & 0.40 & 2 & 2 \\
\hline $2.5 \times 40 \mathrm{~mm}$ & 0.021 & 4.03 & 20.54 & 21.41 & 3.82 & 0.40 & 2 & 2 \\
\hline \multicolumn{9}{|l|}{ B0-HDPE 20\% } \\
\hline $10 \times 10 \mathrm{~mm}$ & 0.021 & 4.03 & 20.54 & 21.41 & 3.82 & 0.81 & 2 & 2 \\
\hline $5 \times 20 \mathrm{~mm}$ & 0.021 & 4.03 & 20.54 & 21.41 & 3.82 & 0.81 & 2 & 2 \\
\hline $2.5 \times 40 \mathrm{~mm}$ & 0.021 & 4.03 & 20.54 & 21.41 & 3.82 & 0.81 & 2 & 2 \\
\hline $\begin{array}{c}\mathrm{f}^{\prime} \mathrm{c} 10 \\
\mathrm{f}^{\prime} \mathrm{c} 10-\mathrm{HDPE} \\
2.5 \%\end{array}$ & 0.021 & 6.25 & 17.55 & 21.49 & 4.03 & 0 & 2 & 2 \\
\hline $10 \times 10 \mathrm{~mm}$ & 0.021 & 6.25 & 17.55 & 21.49 & 4.03 & 0.16 & 2 & 2 \\
\hline $5 \times 20 \mathrm{~mm}$ & 0.021 & 6.25 & 17.55 & 21.49 & 4.03 & 0.16 & 2 & 2 \\
\hline $2.5 \times 40 \mathrm{~mm}$ & 0.021 & 6.25 & 17.55 & 21.49 & 4.03 & 0.16 & 2 & 2 \\
\hline $\begin{array}{c}\mathrm{f}^{\prime} \mathrm{c} 10-\mathrm{HDPE} \\
5 \%\end{array}$ & & & & & & & & \\
\hline $10 \times 10 \mathrm{~mm}$ & 0.021 & 6.25 & 17.55 & 21.49 & 4.03 & 0.31 & 2 & 2 \\
\hline $5 \times 20 \mathrm{~mm}$ & 0.021 & 6.25 & 17.55 & 21.49 & 4.03 & 0.31 & 2 & 2 \\
\hline $2.5 \times 40 \mathrm{~mm}$ & 0.021 & 6.25 & 17.55 & 21.49 & 4.03 & 0.31 & 2 & 2 \\
\hline
\end{tabular}


Table 4. Cont.

\begin{tabular}{|c|c|c|c|c|c|c|c|c|}
\hline \multirow{2}{*}{$\begin{array}{c}\text { HDPE } \\
\text { Addition }\end{array}$} & \multirow{2}{*}{$\begin{array}{l}\text { Volume of } \\
\text { Concrete } \\
\left(\mathrm{m}^{3}\right)\end{array}$} & \multirow[b]{2}{*}{ Cement (kg) } & \multirow{2}{*}{$\begin{array}{c}\text { Fine } \\
\text { Aggregate } \\
\text { (kg) }\end{array}$} & \multirow{2}{*}{$\begin{array}{c}\text { Coarse } \\
\text { Aggregate } \\
\text { (kg) }\end{array}$} & \multirow[b]{2}{*}{$\begin{array}{l}\text { Water } \\
(\mathbf{k g})\end{array}$} & \multirow{2}{*}{$\begin{array}{l}\text { HDPE } \\
\text { Lamellar } \\
\quad(\mathbf{k g})\end{array}$} & \multicolumn{2}{|c|}{ Number of Specimens } \\
\hline & & & & & & & $\begin{array}{l}\text { Compressive } \\
\text { Strength }\end{array}$ & $\begin{array}{l}\text { Tensile } \\
\text { Strength }\end{array}$ \\
\hline $\begin{array}{c}f^{\prime} c 10-H D P E \\
10 \%\end{array}$ & & & & & & & & \\
\hline $10 \times 10 \mathrm{~mm}$ & 0.021 & 6.25 & 17.55 & 21.49 & 4.03 & 0.63 & 2 & 2 \\
\hline $5 \times 20 \mathrm{~mm}$ & 0.021 & 6.25 & 17.55 & 21.49 & 4.03 & 0.63 & 2 & 2 \\
\hline $\begin{array}{c}2.5 \times 40 \mathrm{~mm} \\
\mathbf{f}^{\prime} \mathbf{c} \mathbf{1 0 - H D P E} \\
\mathbf{2 0 \%}\end{array}$ & 0.021 & 6.25 & 17.55 & 21.49 & 4.03 & 0.63 & 2 & 2 \\
\hline $10 \times 10 \mathrm{~mm}$ & 0.021 & 6.25 & 17.55 & 21.49 & 4.03 & 1.25 & 2 & 2 \\
\hline $5 \times 20 \mathrm{~mm}$ & 0.021 & 6.25 & 17.55 & 21.49 & 4.03 & 1.25 & 2 & 2 \\
\hline $2.5 \times 40 \mathrm{~mm}$ & 0.021 & 6.25 & 17.55 & 21.49 & 4.03 & 1.25 & 2 & 2 \\
\hline $\begin{array}{c}\mathbf{f}^{\prime} \mathrm{c} 25 \\
\mathrm{f}^{\prime} \mathrm{c} 25-\mathrm{HDPE} \\
2.5 \%\end{array}$ & 0.021 & 8.75 & 14.56 & 25.09 & 4.56 & 0.00 & 2 & 2 \\
\hline $10 \times 10 \mathrm{~mm}$ & 0.021 & 8.75 & 14.56 & 25.09 & 4.56 & 0.22 & 2 & 2 \\
\hline $5 \times 20 \mathrm{~mm}$ & 0.021 & 8.75 & 14.56 & 25.09 & 4.56 & 0.22 & 2 & 2 \\
\hline $\begin{array}{c}2.5 \times 40 \mathrm{~mm} \\
\mathbf{f}^{\prime} \mathbf{c} \mathbf{2 5 - H D P E} \\
\mathbf{5 \%}\end{array}$ & 0.021 & 8.75 & 14.56 & 25.09 & 4.56 & 0.22 & 2 & 2 \\
\hline $10 \times 10 \mathrm{~mm}$ & 0.021 & 8.75 & 14.56 & 25.09 & 4.56 & 0.44 & 2 & 2 \\
\hline $5 \times 20 \mathrm{~mm}$ & 0.021 & 8.75 & 14.56 & 25.09 & 4.56 & 0.44 & 2 & 2 \\
\hline $\begin{array}{c}2.5 \times 40 \mathrm{~mm} \\
\mathbf{f}^{\prime} \mathbf{c} \mathbf{2 5 - H D P E} \\
\mathbf{1 0} \%\end{array}$ & 0.021 & 8.75 & 14.56 & 25.09 & 4.56 & 0.44 & 2 & 2 \\
\hline $10 \times 10 \mathrm{~mm}$ & 0.021 & 8.75 & 14.56 & 25.09 & 4.56 & 0.88 & 2 & 2 \\
\hline $5 \times 20 \mathrm{~mm}$ & 0.021 & 8.75 & 14.56 & 25.09 & 4.56 & 0.88 & 2 & 2 \\
\hline $\begin{array}{c}2.5 \times 40 \mathrm{~mm} \\
\mathbf{f}^{\prime} \mathbf{c} 25-\mathrm{HDPE} \\
\mathbf{2 0 \%}\end{array}$ & 0.021 & 8.75 & 14.56 & 25.09 & 4.56 & 0.88 & 2 & 2 \\
\hline $10 \times 10 \mathrm{~mm}$ & 0.021 & 8.75 & 14.56 & 25.09 & 4.56 & 1.75 & 2 & 2 \\
\hline $5 \times 20 \mathrm{~mm}$ & 0.021 & 8.75 & 14.56 & 25.09 & 4.56 & 1.75 & 2 & 2 \\
\hline $2.5 \times 40 \mathrm{~mm}$ & 0.021 & 8.75 & 14.56 & 25.09 & 4.56 & 1.75 & 2 & 2 \\
\hline
\end{tabular}

The terms used are as follows: B0 refers to normal concrete meeting the standard job mix design without the addition of HDPE lamellar, while B0-HDPE 2.5\% refers to B0 concrete with the addition of $2.5 \%$ HDPE. The amount of HDPE lamellar particles for the experimental investigation is calculated on the basis of the weight of the cement used.

This study used cylindrical specimens with a diameter of $150 \mathrm{~mm}$ and a height of $300 \mathrm{~mm}$ (Figure 3). The cylinder molds were made of steel to avoid leakage and hold their integrity under severe use. The mold nonabsorbent material avoids a reaction with Portland or other hydraulic cement. For each test, two samples were used for each size of HDPE lamellar particles. Accordingly, the number of samples used for the splitting tensile and cylindrical compressive strength tests was six. The total number of samples used was 156 , including those for normal concrete testing. Since only two specimens were used for each design, the data were processed as average.

We set a higher water/cement ratio to produce a workable concrete (minimum 0.52). Typically, the minimum water/cement ratio is $0.35-0.4$, as a lower ratio may result in the concrete becoming too dry and unworkable [37]. Furthermore, the use of a higher water/cement ratio results in a high slump value. However, the addition of HDPE plastic sheets compensated for this change. To evaluate the effect of adding HDPE lamellar particles, several tests were conducted, including slump testing using the ASTM C143 standard [38], compressive strength testing using the ASTM C39 standard [39], and tensile strength testing using the ASTM C496 standard [40]. 


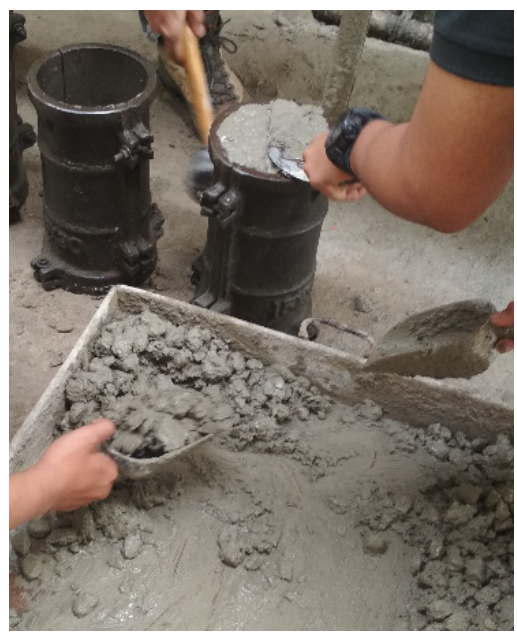

Figure 3. Preparation of concrete cylinder specimen.

\section{The Results}

This study conducted tests to examine the appropriate concrete mixtures incorporating HDPE lamellar particles for non-structural applications to determine the effect of HDPE size and additions on low-quality concrete, medium-quality concrete, and high-quality concrete can be explained as follows.

\subsection{Concrete Slump Test}

Concrete workability is quantified by the concrete slump, which depends on many factors, e.g., mixing methods, concrete materials and admixtures, and the workability changes with time due to those factors. In this slump test, the preparation of specimens using the mold (slump cone) is shown in Figure 4, and the varying HDPE lamellar particles were added to the fresh concrete before testing.

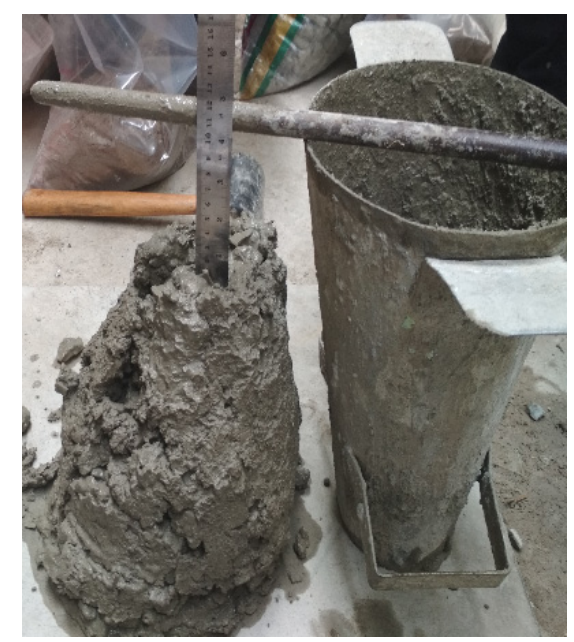

Figure 4. Preparation of B0 concrete for the slump test.

We set the slump value for normal concrete (baseline) to $115-125 \mathrm{~mm}$. As shown in Figure 5, a greater amount of HDPE to the concrete mix led to a smaller slump value. The slump value of B0 concrete (Figure 5a) with HDPE size at $10 \times 10 \mathrm{~mm}$ declined by $10 \%$ for 20\% HDPE lamellar addition (accounted from $120 \mathrm{~mm}$ of normal concrete to $110 \mathrm{~mm}$ ). The lowest percentage reduction at slump value showed up in $\mathrm{f}^{\prime} \mathrm{c} 10$ with HDPE size $10 \times$ $10 \mathrm{~mm}$ (Figure $5 \mathrm{~b}$ ), and the maximum value given by $\mathrm{f}^{\prime} \mathrm{c} 25$ with HDPE size $2.5 \times 40 \mathrm{~mm}$, at $16.7 \%$ (Figure $5 \mathrm{c}$ ). We found, from all the samples used, the maximum value of reduction ranged from 5 to $20 \mathrm{~mm}$ compared to the standard value. 


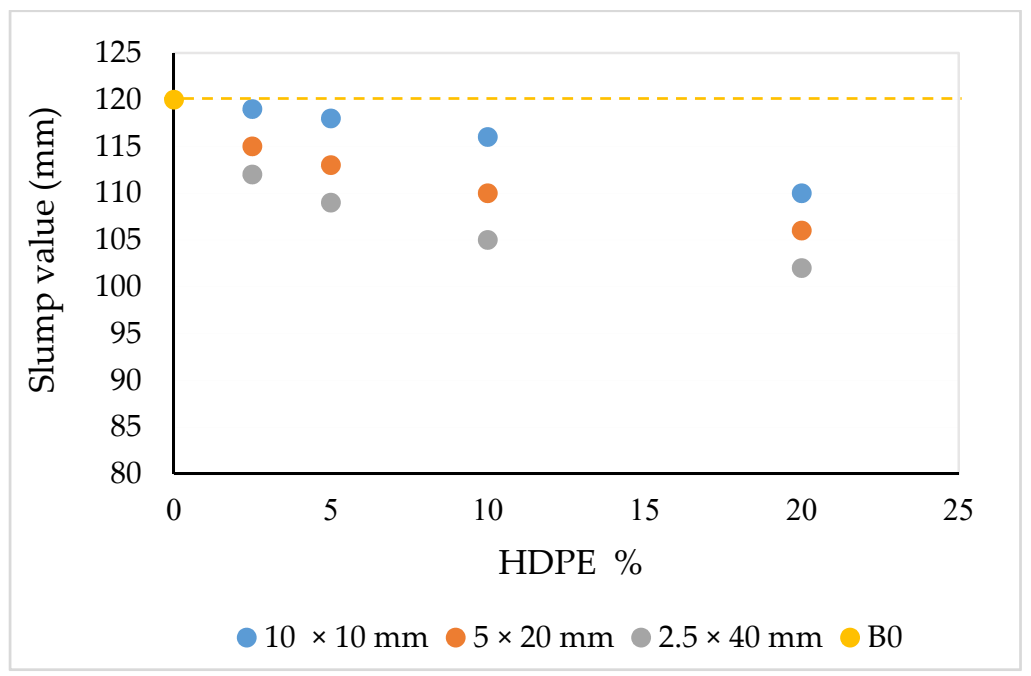

(a)

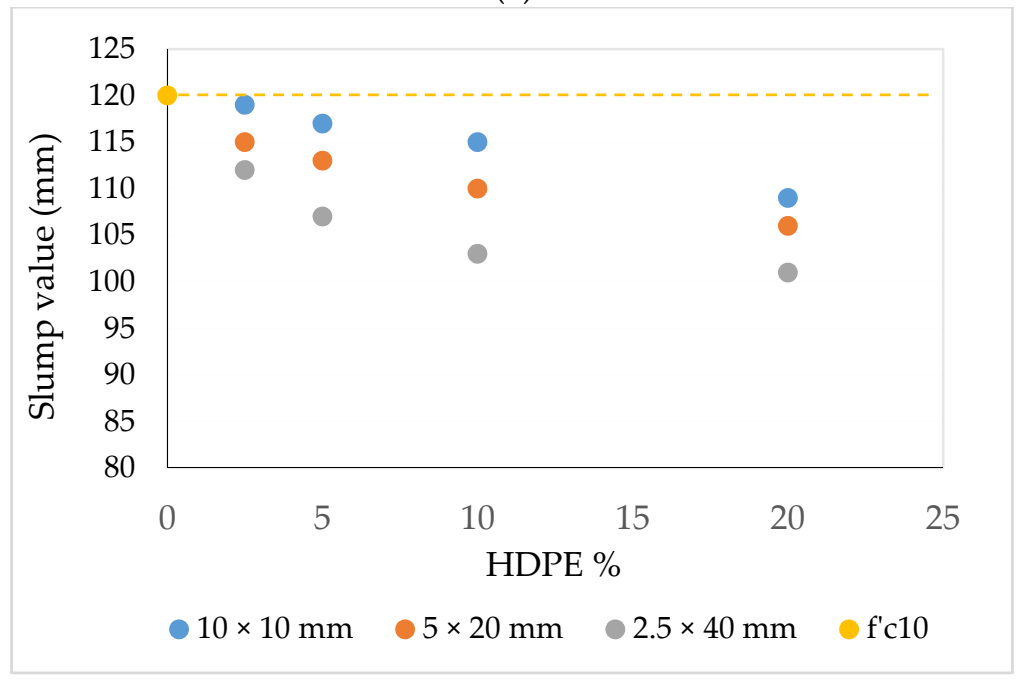

(b)

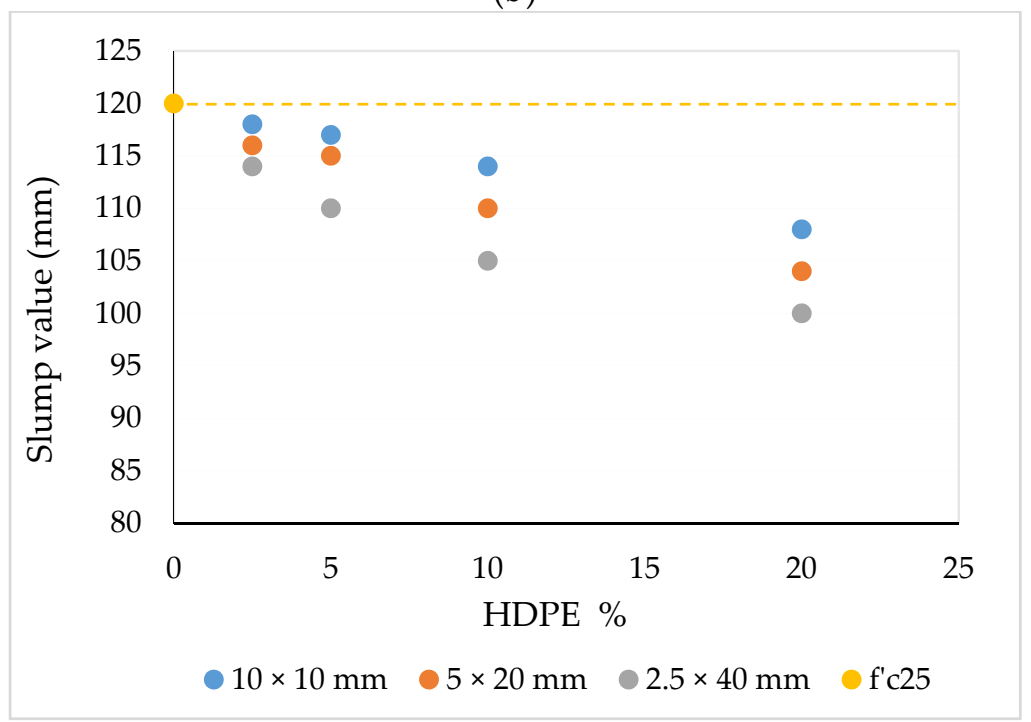

(c)

Figure 5. Slump value as a function of HDPE content (\%) and sizes: (a) B0; (b) f'c10; (c) f f'c25. 


\subsection{Unit Weight of Concrete}

ASTM C29 [34] uses the term unit weight to refer to the concrete property in mass per unit volume. This gives a good indication of sample concrete density. The unit weight for all samples was determined by comparing the specimen's weight with the specimen's substantial volume. The relationship between the unit weight of the concrete, HDPE lamellar content, and its sizes are given in Figure 6. The graphs show that a greater addition of HDPE lamellar particles led to lighter concrete due to the low density of HDPE plastic, which was applied to B0, f'c10, and f'c25. However, the size of the HDPE sheets did not affect the concrete unit weight, as they all showed a similar value for certain percentages. For example, in Figure $6 \mathrm{~b}$, the unit weight of $20 \%$ additions was $2011 \mathrm{~kg} / \mathrm{m}^{3}, 2013 \mathrm{~kg} / \mathrm{m}^{3}$, and $2012 \mathrm{~kg} / \mathrm{m}^{3}$ for HDPE sizes of " $10 \times 10 \mathrm{~mm}$ ", " $5 \times 20 \mathrm{~mm}$ ", and "2.5 $\times 40 \mathrm{~mm}$ " respectively.

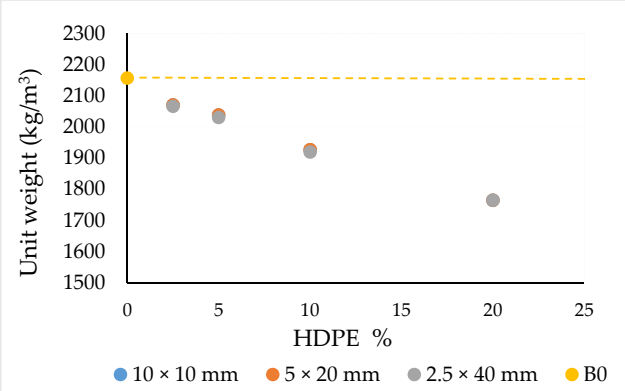

(a)

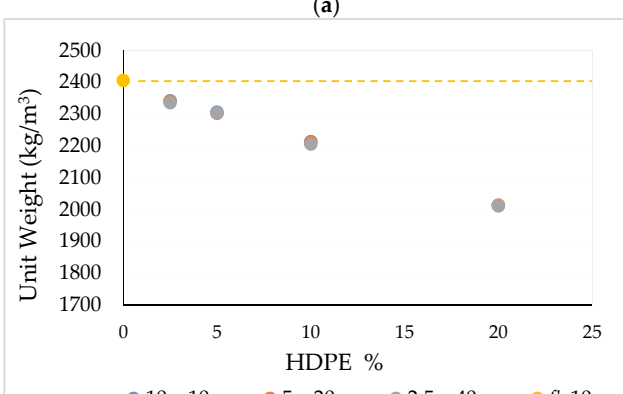

(b)

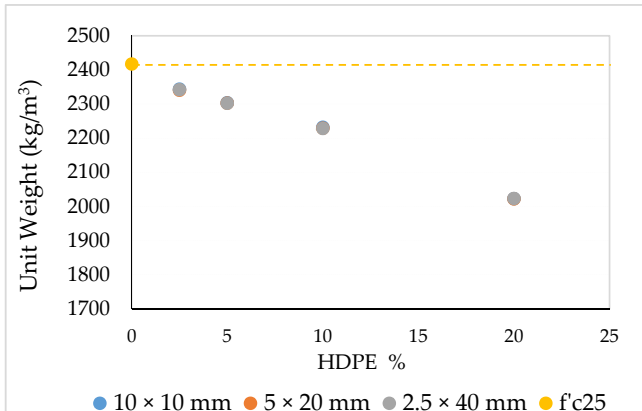

(c)

Figure 6. The relationship between concrete unit weight and HDPE content and sizes: (a) B0; (b) f'c10; (c) f'c25.

\subsection{Tensile and Compressive Strength}

Tensile and compressive strengths are the important mechanical properties that identify concrete performance. Figures 7 and 8 display the results of splitting tensile and cylindrical compressive strength tests for the concrete mixtures containing HDPE addition (the testing results are shown in Appendix A). Our experiments indicated that the strength varied depending on the HDPE content and sizes. 


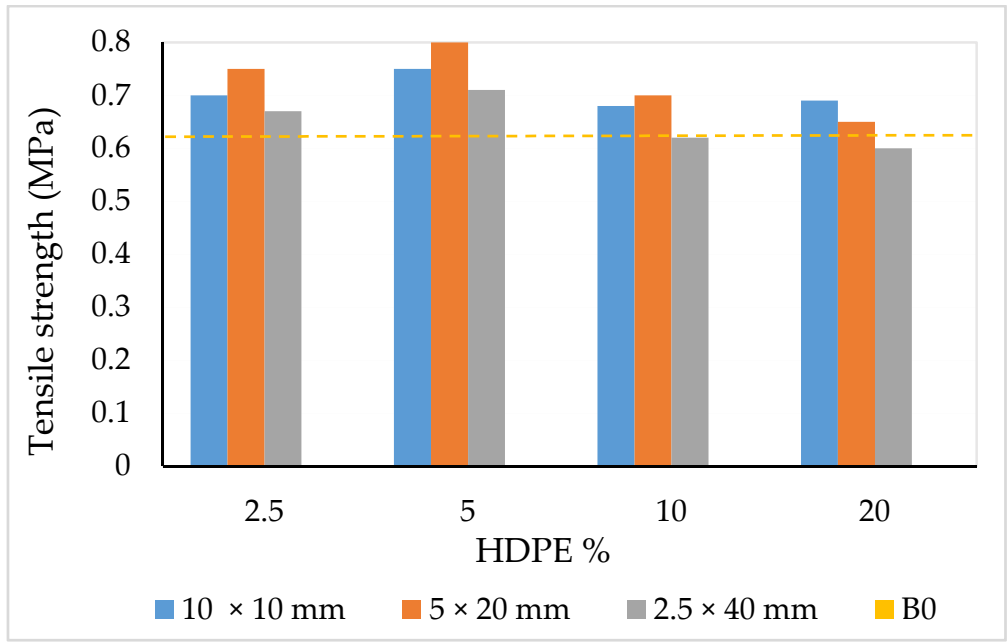

(a)

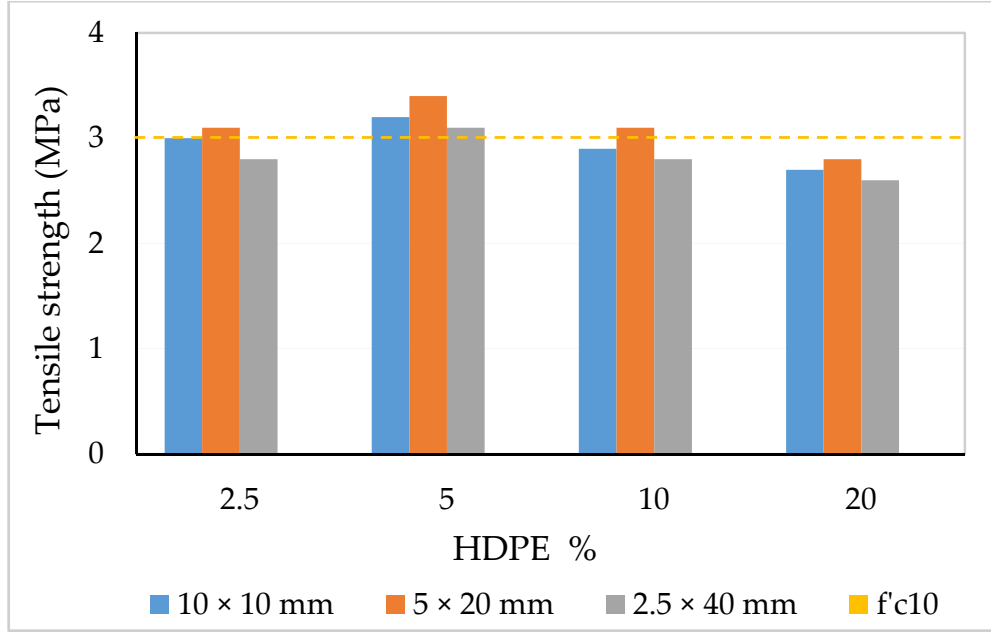

(b)

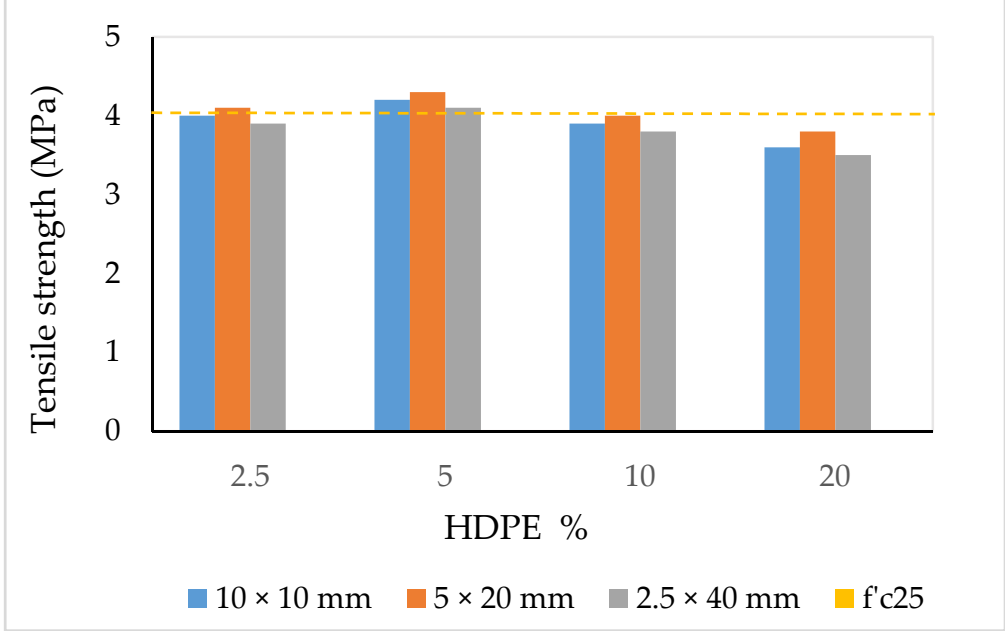

(c)

Figure 7. Tensile strength of concrete mixtures as a function of HDPE content and lamellar shape: (a) B0; (b) f'c10 MPa; (c) f'c25 MPa. 


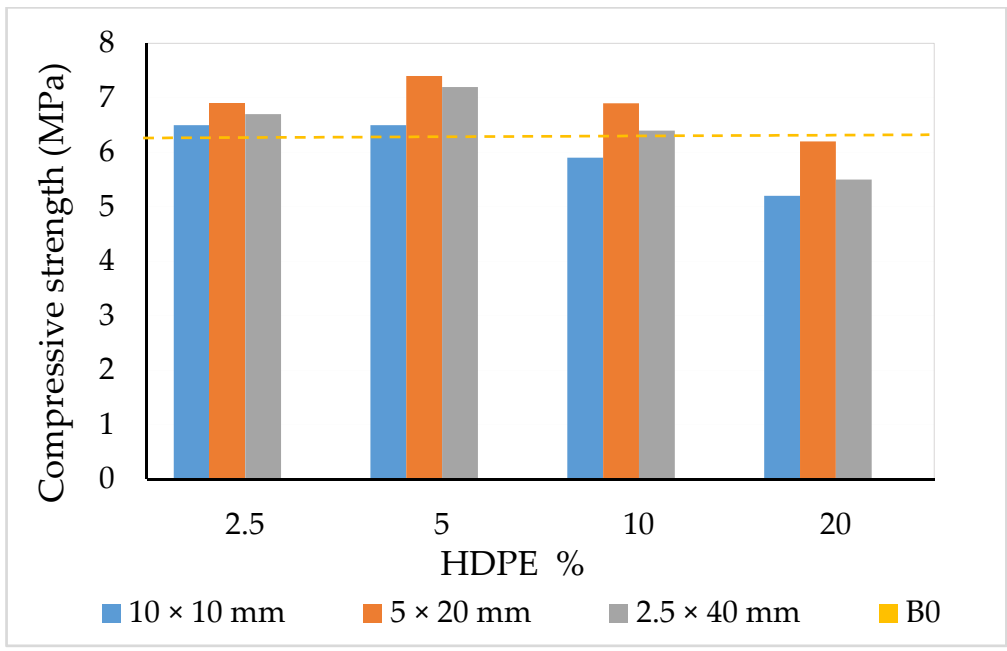

(a)

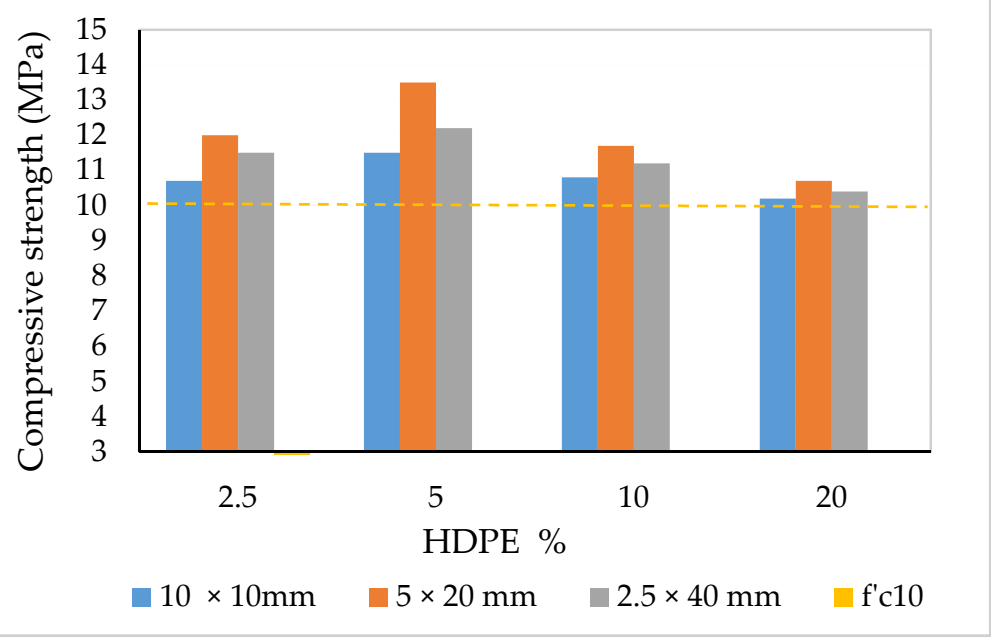

(b)

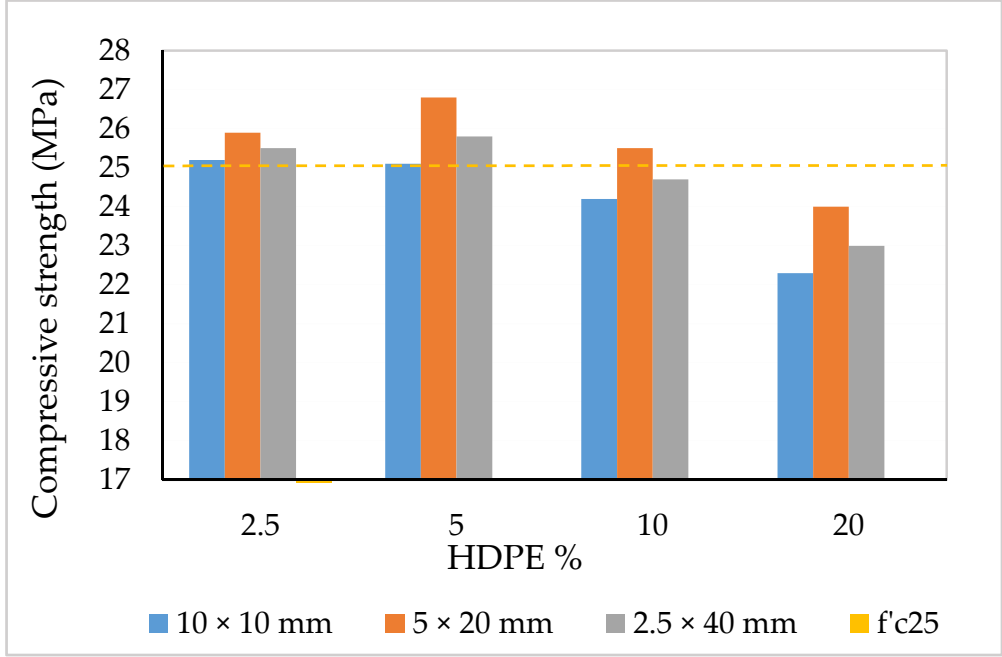

(c)

Figure 8. Compressive strength of concrete mixtures as a function of HDPE content and lamellar shape: (a) B0; (b) f'c10 MPa; (c) f'c25 MPa.

In line with the job mix design shown in Table 3, the concrete aggregate content and $w / c$ ratio had an effect on tensile and compressive strength. Figure 7 shows that the B0 concrete had a lower tensile strength, compared to $f^{\prime} c 10$ and $f^{\prime} c 25$. We observed also 
that the percentage and HDPE sizes behaved differently on concrete strength. Although all sizes of HDPE lamellar had an equal surface area $\left(1 \mathrm{~cm}^{2}\right)$, they produced a different response. In this case, we found that for all concrete classes, the addition of HDPE up to $5 \%$ showed higher tensile strength compared to other percentages (above the baseline), and the " $5 \times 20 \mathrm{~mm}^{\prime}$ was the best shape compared to the size of " $10 \times 10 \mathrm{~mm}$ " and " $2.5 \times 40 \mathrm{~mm}$ ". This finding aligned with the compressive strength results shown in Figure $8 \mathrm{a}-\mathrm{c}$, where the $5 \%$ addition and " $5 \times 20 \mathrm{~mm}$ " strength value was above the normal concrete quality. This graph also indicates that $\mathrm{f}^{\prime} \mathrm{c} 10$ concrete gave a better response to the increase in concrete quality compared to $\mathrm{B} 0$ and $\mathrm{f}^{\prime} \mathrm{c} 25$, where in all percentage additions and different lamellar shapes, the value was above the normal concrete.

In addition, for the compaction, Figure 9a,b shows a two-dimensional (2D) image of HDPE positions in the concrete mixture. The lamellar particles with sizes of "10 $\times 10 \mathrm{~mm}$ " and " $5 \times 20 \mathrm{~mm}$ " remained unaffected by coarse aggregate pressure during casting. When tested for compressive strength, the broken piece of concrete was then observed visually. The size of $10 \times 10 \mathrm{~mm}$ and $5 \times 20 \mathrm{~mm}$ seemed to pack and bond together with the concrete mixture in a straight position. However, we found that the " $2.5 \times 40 \mathrm{~mm}$ " sheet became curved during casting (Figure 9c). Though this condition depends on the different angles of lamellar particles and the level of coarse aggregate pressure received during casting, the results showed that the $5 \times 20 \mathrm{~mm}$ specimens performed better compared to $2.5 \times 40 \mathrm{~mm}$.

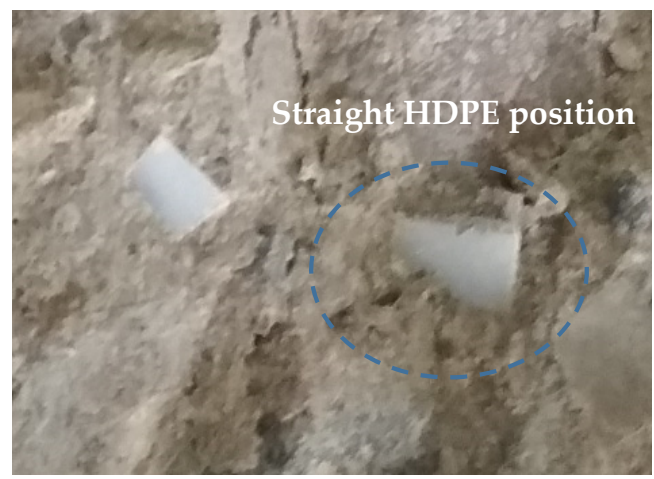

(a)

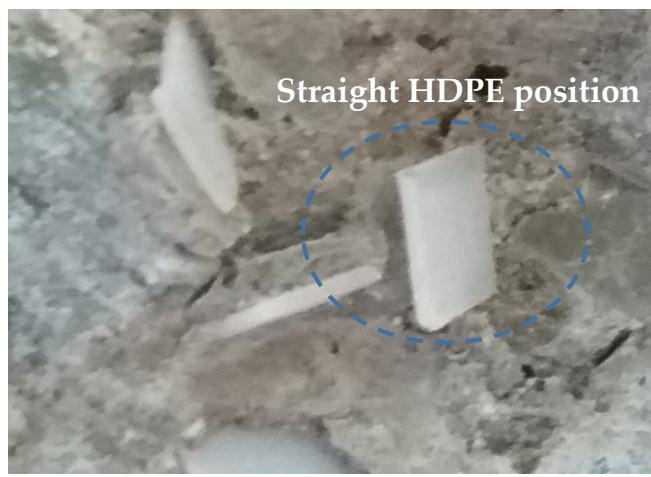

(b)

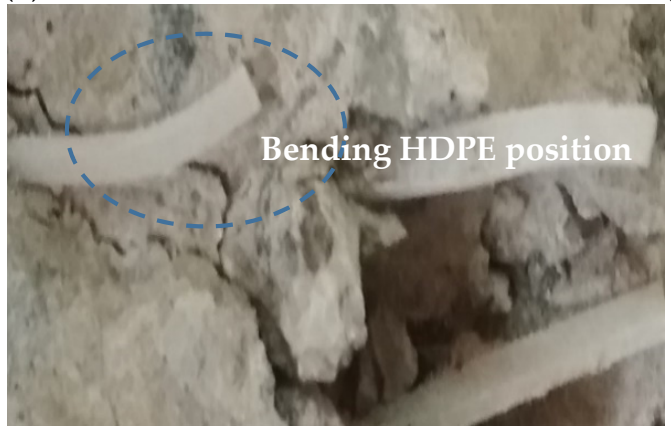

(c)

Figure 9. 2D images of HDPE in concrete: (a) $10 \times 10 \mathrm{~mm}$; (b) $5 \times 20 \mathrm{~mm}$; (c) $2.5 \times 40 \mathrm{~mm}$.

\section{Discussion and Analysis}

\subsection{Relationship between HDPE Additions and Slump Value}

The concrete workability indicates the consistency of the concrete mix during the work. It relates to the degree of its compaction provided by the external (contact with the surface) and internal friction (given by the aggregate size, shape, grading). The use of admixtures, e.g., plastics could also affect the compaction. The fact that plastic materials are generally lightweight and resistant to weather, means that they can be considered as suitable additive materials for concrete [19]. Previous studies indicated that added materials, including plastics, can improve the properties of concrete given appropriate percentage mixes $[9,28]$. 
In this case, the addition of plastic can improve toughness and energy absorption at postcracking [41,42]. Further, given the very poor biodegradability of plastic, i.e., HDPE, can not only improve the long-term performance of concrete structures but it can also contribute to environmental sustainability and performance of the construction industry [43,44].

However, the addition of HDPE to the concrete mixture affected the slump value, which is essential for concrete workability. Good workability is associated with the finishing stages, homogeneity, and resistance to segregation. In regard to segregation, this must be avoided during casting, due to fresh concrete's low workability [45]. Increasing the amount of water used in the job mix and adding materials at proportioning mix to maintain concrete density [46] could be useful. For instance, recently, two types of added plastic have been used in concrete mixes and have shown satisfactory results when using $30 \%$ plastic waste in the total aggregate [47]. Therefore, to prevent less fluidity in the first place, we managed the $w / c$ ratio and admixture additions that function to alter concrete properties when making the job mixes. Table 3 shows we set a higher $w / c$ ratio than the typical $w / c$ ratio, and we used a lamellar shape (bigger size than fiber).

Even so, our findings, shown in Figure 5, identified that a small amount of added plastic does not affect the mixture's workability, but a higher percentage of added plastic was found to influence the cementitious materials' content and sharply decrease the concrete's workability. The possible reason is plastic hydrophobicity, which causes an insufficiency of plastics to mix with other materials. It may limit the hydration of cement as a result of the lesser bonding between plastic surfaces and cement paste. Additionally, due to the angular and nonuniform nature of plastic aggregate particles $[28,48]$, the increase of HDPE lamellar particles in the concrete mixture results in lower fluidity compared to normal concrete. This applies to different sizes of plastic lamellar particles, as seen in Figure 5, which clearly indicates that, for all additions of HDPE at different sizes, the addition of HDPE lamellar particles thickened the concrete mixture, thereby lowering the slump value. To sum up, when considering the range of slump reduction, the added HDPE lamellar particles fit well for low-degree workability applications. We consider that the findings of this study may be useful for non-structural works, where higher strength is not the main aspect $[49,50]$.

\subsection{Relationship between HDPE Additions and Unit Weight}

When the HDPE lamellar particles were added into the concrete mixture, due to the nature of plastic (e.g., immiscibility), the addition of plastic in the mixture may increase the air content in concrete, thus affecting its density [19]. Additionally, during the hydration and curing process, some amount of moisture is removed from the concrete mixture. The immiscibility of plastics could affect compactness when a certain level of admixture is replaced by HDPE. However, here, the volume of concrete remains the same, as indicated by the amount pushed out of the sample mold. Further, as the unit weight of normal concrete is about $2400 \mathrm{~kg} / \mathrm{m}^{3}$; higher than HDPE, which is about $930-970 \mathrm{~kg} / \mathrm{m}^{3}$, it is justifiable that concrete containing HDPE additions would have lower unit weight. Figure 6 shows that for all concrete classes, compared to normal concrete, the unit weight of the concrete mixture dropped linearly with the increased number of lamellar particles in the mixture. Thus, an increase in HDPE content enables a reduction in concrete weight; an important target in construction. In particular, for the same percentage of HDPE lamellar additions, the different size of plastic lamellar particles does not affect the unit weight. This finding is indicated by an almost similar value of unit weight for " $5 \times 20 \mathrm{~mm}$ ", "2.5 $\times 40 \mathrm{~mm}$ ", and " $10 \times 10 \mathrm{~mm}$ " lamellar particles.

Further, this study identified that the addition of HDPE, in lamellar shape, provided the best response to concrete quality up to $5 \%$ for medium concrete strength of $\mathrm{f}^{\prime} \mathrm{c} 10$. This type of concrete could add benefit to non-structural walls, base concrete in the rigid pavement on highways, paving blocks for parking lots with low loads, wall panels, shotcrete (or Gunite), and concrete footpaths. For the use of precast concrete walls especially, concrete mixtures containing HDPE could reduce the building's structural load and energy 
consumption within the building by lowering the inside temperature. Together with fillers (e.g., sand, quarry fine), this type of concrete mix could help prevent heat transfer within a structure, which is relevant to Indonesia's moderate to high temperatures. In particular, there is a strong connection between thermal conductivity and concrete's substantial weight whereby the use of plastics to replace aggregates can reduce concrete's thermal conductivity compared to bare concrete [9,51].

Although the previous study has discussed the development of lightweight concrete using HDPE additions (25\%), opening up new development opportunities for nonstructural and structural applications [52], our findings show that the concrete with added plastics should be directed to medium concrete strength. Therefore, mean concrete containing plastics cannot be used as a primary construction material, i.e., for column, beam, and plate constructions, mainly due to safety factors and its poor fire-resistant behavior [50]. These findings have an impact and add to the development of lightweight concrete for the green construction sector. Thus, the addition of HDPE could also lead to a more sustainable approach to reducing plastic waste.

\subsection{The Effect of HDPE Additions to Tensile and Compressive Strength}

As stated earlier, previous studies have found a relationship between plastics addition influencing concrete's tensile strength and compressive strength $[19,21,53]$ matching those of steel fibers that affected the value of splitting tensile and compressive strength [54], as well as plastic fibers, carbon fibers, and fibers from natural materials, such as flax or other plants. According to Hasan et al. [41], inserting fibers into a concrete mixture can increase the concrete composite's tensile strength by about $10-15 \%$, compared to standard concrete. Other research found similar results that fibers can prevent brittle failure and enhance the ductility of the concrete $[48,52,54]$.

The tensile strength is an essential determinant of how concrete performs under induced stress. Figures 7 and 8 show the connection between tensile and compressive strength; although their relationship is not directly proportional. The higher the compressive strength, the higher the tensile strength, but at a decreasing rate [55]. This study indicates that the addition of 5\% HDPE increases the tensile and compressive strength of concrete, better than $2.5 \%, 10 \%$, and $20 \%$. Furthermore, the addition of $10 \%$ and $20 \%$ HDPE content to $\mathrm{B} 0$ and $\mathrm{f}^{\prime} \mathrm{c} 25$ concrete reduced the tensile and compressive strength. This finding in line with other studies showing that increasing the volume fraction can affect fiber bonding and decrease the strength of concrete composites $[15,25,51]$. However, this study identified that this did not apply to $\mathrm{f}^{\prime} \mathrm{c} 10 \mathrm{MPa}$ concrete, where an increase in quality occurred, even with a content of $20 \%$ for sheets with a size of $5 \times 20 \mathrm{~mm}(13 \%$ increase in splitting tensile strength; $35 \%$ increase in compressive strength). Therefore, the amount of added HDPE should be chosen on the basis of the weight of the cement used, as outlined in Table 2.

Further, since all HDPE samples added had the same cross-sectional area, the size largely determines the results, whereby the position of plastic lamellar particles in the concrete can reduce the optimality of the aggregate bond, as seen in Figure 9. The findings emphasized that even though the plastic lamellar particles have the same cross-sectional area, different results came because their position depends on the pressure received. This explains why some lamellar particles are curved and some are straight. Figures 7 and 8 show that in particular for lamellar particles at a size of "10 $\times 10 \mathrm{~mm}$ ", the plastic lamellar particles are packed together in a straight position, but in terms of its capacity to withstand loads, the size of " $5 \times 20 \mathrm{~mm}$ " produced a better response compared to "10 $\times 10 \mathrm{~mm}$ ". It shows that the length of the lamellar particles is important, up to a certain size. In summary, the performance of the additions with respect to strength testing was in the order of $5 \times 20 \mathrm{~mm}>2.5 \times 40 \mathrm{~mm}>10 \times 10 \mathrm{~mm}$. Thus, the use of HDPE with a size of $5 \times 20 \mathrm{~mm}$ as an additive in the concrete mixture was acceptable. 


\section{Conclusions and Recommendations for Future Research}

Few studies have assessed the effect of added particles' length on concrete properties. This study has contributed to the understanding of the optimal percentages and sizes of HDPE in the shape of lamellar particles in concrete. Our study contributes to showing the effect that HDPE additions have in terms of size and percentage on concrete qualities to improve its use and exploitation and to design the concrete mix design process. Some important findings are:

(1). This study evaluated the use of $2.5 \%, 5 \%, 10 \%$, and 20\% HDPE lamellar particle additions at sizes of $10 \times 10 \mathrm{~mm}, 0.5 \times 20 \mathrm{~mm}$, and $2.5 \times 40 \mathrm{~mm}$ incorporated into three concrete types (B0, $\mathrm{f}^{\prime} \mathrm{c} 10$, and $\left.\mathrm{f}^{\prime} \mathrm{c} 25\right)$. The $\mathrm{f}^{\prime} \mathrm{c} 10 \mathrm{MPa}$ concrete performed best in response to the addition of lamellar particles, whereas $5 \%$ was the optimal HDPE content, and $5 \times 20 \mathrm{~mm}$ was the optimal size.

(2). All variants of HDPE lamellar particles described can be used with f'c10 MPa concrete. However, only $5 \times 20 \mathrm{~mm}$ HDPE sheets should be used with B0 and f'c25 MPa concrete.

(3). Future research should investigate $\mathrm{f}^{\prime} \mathrm{c} 10 \mathrm{MPa}$ to determine the effects of different percentage additions and material composition into concrete mixes. Additionally, further work is needed to identify whether similar effects apply to different plastic shapes. More testing could explore the valuation of physical concrete properties, e.g., water porosity.

Author Contributions: T.; conceptualization, design and analysis, investigation, initial draft, visualization; J.N.; draft preparation, administration process, and the editing process. All authors have read and agreed to the published version of the manuscript.

Funding: This research received no external funding.

Data Availability Statement: All data is contained within the article.

Acknowledgments: We thank our colleagues in the Department of Civil Engineering, Mulawarman University, who help and provide us their insight and suggestions that greatly assisted our research.

Conflicts of Interest: The authors declare no conflict of interest associated with this publication. There has been no significant financial support for this work that could have influenced its outcome.

\section{Appendix A}

Table A1. Compressive and Tensile Test Results of 156 Specimens Used.

\begin{tabular}{|c|c|c|c|c|c|c|}
\hline \multirow{3}{*}{ HDPE Addition } & \multicolumn{3}{|c|}{ Compressive Test (MPa) } & \multicolumn{3}{|c|}{ Tensile Test (MPa) } \\
\hline & \multicolumn{3}{|c|}{ Number of Specimens } & \multicolumn{3}{|c|}{ Number of Specimens } \\
\hline & 1 & 2 & Average & 1 & 2 & Average \\
\hline B0 & 6.40 & 6.30 & 6.35 & 0.60 & 0.68 & 0.64 \\
\hline \multicolumn{7}{|l|}{ B0-HDPE 2.5\% } \\
\hline $10 \times 10 \mathrm{~mm}$ & 6.30 & 6.70 & 6.50 & 0.70 & 0.70 & 0.70 \\
\hline $5 \times 20 \mathrm{~mm}$ & 6.80 & 7.00 & 6.90 & 0.80 & 0.70 & 0.75 \\
\hline $2.5 \times 40 \mathrm{~mm}$ & 6.80 & 6.60 & 6.70 & 0.70 & 0.65 & 0.68 \\
\hline \multicolumn{7}{|l|}{ B0-HDPE 5\% } \\
\hline $10 \times 10 \mathrm{~mm}$ & 6.40 & 6.60 & 6.50 & 0.70 & 0.80 & 0.75 \\
\hline $5 \times 20 \mathrm{~mm}$ & 7.40 & 7.40 & 7.40 & 0.80 & 0.80 & 0.80 \\
\hline $2.5 \times 40 \mathrm{~mm}$ & 7.15 & 7.25 & 7.20 & 0.70 & 0.74 & 0.72 \\
\hline \multicolumn{7}{|l|}{ B0-HDPE 10\% } \\
\hline $10 \times 10 \mathrm{~mm}$ & 5.90 & 6.00 & 5.95 & 0.70 & 0.65 & 0.68 \\
\hline $5 \times 20 \mathrm{~mm}$ & 6.90 & 6.90 & 6.90 & 0.70 & 0.70 & 0.70 \\
\hline $2.5 \times 40 \mathrm{~mm}$ & 6.40 & 6.42 & 6.41 & 0.64 & 0.60 & 0.62 \\
\hline \multicolumn{7}{|l|}{ B0-HDPE 20\% } \\
\hline $10 \times 10 \mathrm{~mm}$ & 5.20 & 5.20 & 5.20 & 0.69 & 0.69 & 0.69 \\
\hline $5 \times 20 \mathrm{~mm}$ & 6.20 & 6.20 & 6.20 & 0.65 & 0.66 & 0.66 \\
\hline $2.5 \times 40 \mathrm{~mm}$ & 5.50 & 5.45 & 5.48 & 0.60 & 0.60 & 0.60 \\
\hline
\end{tabular}


Table A1. Cont.

\begin{tabular}{|c|c|c|c|c|c|c|}
\hline \multirow{3}{*}{ HDPE Addition } & \multicolumn{3}{|c|}{ Compressive Test (MPa) } & \multicolumn{3}{|c|}{ Tensile Test (MPa) } \\
\hline & \multicolumn{3}{|c|}{ Number of Specimens } & \multicolumn{3}{|c|}{ Number of Specimens } \\
\hline & 1 & 2 & Average & 1 & 2 & Average \\
\hline $\mathrm{f}^{\prime} \mathrm{c} 10$ & 10.05 & 10.00 & 10.03 & 3.00 & 3.00 & 3.00 \\
\hline \multicolumn{7}{|l|}{$f^{\prime} \mathrm{c} 10-\mathrm{HDPE} 2.5 \%$} \\
\hline $10 \times 10 \mathrm{~mm}$ & 10.70 & 10.70 & 10.70 & 2.80 & 3.20 & 3.00 \\
\hline $5 \times 20 \mathrm{~mm}$ & 12.00 & 12.00 & 12.00 & 2.90 & 3.30 & 3.10 \\
\hline $2.5 \times 40 \mathrm{~mm}$ & 11.30 & 11.70 & 11.50 & 2.70 & 2.90 & 2.80 \\
\hline \multicolumn{7}{|l|}{$f^{\prime} \mathrm{c} 10$-HDPE $5 \%$} \\
\hline $10 \times 10 \mathrm{~mm}$ & 11.50 & 11.50 & 11.50 & 3.20 & 3.15 & 3.18 \\
\hline $5 \times 20 \mathrm{~mm}$ & 13.50 & 13.50 & 13.50 & 3.30 & 3.45 & 3.38 \\
\hline $2.5 \times 40 \mathrm{~mm}$ & 12.20 & 12.17 & 12.19 & 3.10 & 3.15 & 3.13 \\
\hline \multicolumn{7}{|l|}{$f^{\prime} c 10-H D P E ~ 10 \%$} \\
\hline $10 \times 10 \mathrm{~mm}$ & 10.80 & 10.80 & 10.80 & 2.80 & 3.00 & 2.90 \\
\hline $5 \times 20 \mathrm{~mm}$ & 11.71 & 11.68 & 11.70 & 3.20 & 3.00 & 3.10 \\
\hline $2.5 \times 40 \mathrm{~mm}$ & 11.20 & 11.20 & 11.20 & 2.65 & 2.90 & 2.78 \\
\hline \multicolumn{7}{|l|}{$\mathrm{f}^{\prime} \mathrm{c} 10$-HDPE $20 \%$} \\
\hline $10 \times 10 \mathrm{~mm}$ & 10.20 & 10.20 & 10.20 & 2.60 & 2.80 & 2.70 \\
\hline $5 \times 20 \mathrm{~mm}$ & 10.68 & 10.72 & 10.70 & 2.80 & 2.85 & 2.83 \\
\hline $2.5 \times 40 \mathrm{~mm}$ & 10.40 & 10.40 & 10.40 & 2.60 & 2.70 & 2.65 \\
\hline $\mathrm{f}^{\prime} \mathrm{c} 25$ & 25.00 & 25.10 & 25.05 & 4.00 & 4.10 & 4.05 \\
\hline \multicolumn{7}{|l|}{$f^{\prime} \mathrm{c} 25-$ HDPE $2.5 \%$} \\
\hline $10 \times 10 \mathrm{~mm}$ & 25.40 & 25.00 & 25.20 & 4.10 & 4.00 & 4.05 \\
\hline $5 \times 20 \mathrm{~mm}$ & 25.50 & 26.30 & 25.90 & 4.15 & 4.10 & 4.13 \\
\hline $2.5 \times 40 \mathrm{~mm}$ & 25.30 & 25.70 & 25.50 & 3.80 & 3.98 & 3.89 \\
\hline \multicolumn{7}{|l|}{$f^{\prime} \mathrm{c} 25-\mathrm{HDPE} 5 \%$} \\
\hline $10 \times 10 \mathrm{~mm}$ & 25.00 & 25.20 & 25.10 & 4.20 & 4.15 & 4.18 \\
\hline $5 \times 20 \mathrm{~mm}$ & 26.60 & 27.00 & 26.80 & 4.30 & 4.35 & 4.33 \\
\hline $2.5 \times 40 \mathrm{~mm}$ & 26.10 & 25.50 & 25.80 & 4.20 & 4.10 & 4.15 \\
\hline \multicolumn{7}{|l|}{$\mathrm{f}^{\prime} \mathrm{c} 25-\mathrm{HDPE} 10 \%$} \\
\hline $10 \times 10 \mathrm{~mm}$ & 24.40 & 24.00 & 24.20 & 3.80 & 3.90 & 3.85 \\
\hline $5 \times 20 \mathrm{~mm}$ & 25.60 & 25.40 & 25.50 & 4.00 & 3.90 & 3.95 \\
\hline $2.5 \times 40 \mathrm{~mm}$ & 24.40 & 25.00 & 24.70 & 3.90 & 3.70 & 3.80 \\
\hline \multicolumn{7}{|l|}{$f^{\prime} c 25-H D P E ~ 20 \%$} \\
\hline $10 \times 10 \mathrm{~mm}$ & 22.60 & 22.00 & 22.30 & 3.70 & 3.60 & 3.65 \\
\hline $5 \times 20 \mathrm{~mm}$ & 24.50 & 23.60 & 24.05 & 3.90 & 3.72 & 3.81 \\
\hline $2.5 \times 40 \mathrm{~mm}$ & 22.90 & 23.10 & 23.00 & 3.50 & 3.52 & 3.51 \\
\hline
\end{tabular}

\section{References}

1. The Association of Plastic Recyclers (APR): Recognition Program Operating Procedures. Available online: https:// plasticsrecycling.org/images/pdf/Recognition_Program/Procedure/Recognition_ProgramOperating_Procedures_June_ 2009.pdf (accessed on 27 May 2020).

2. How Long It Takes for Some Everyday Items to Decompose. Available online: http://storage.neic.org/event/docs/1129/how long_does_it_take_garbage_to_decompose.pdf (accessed on 27 May 2020).

3. Verma, R.; Vinoda, K.; Papireddy, M.; Gowda, A. Toxic Pollutants from Plastic Waste-A Review. Procedia Environ. Sci. 2016, 35, 701-708. [CrossRef]

4. Lebreton, L.C.M.; Van Der Zwet, J.; Damsteeg, J.-W.; Slat, B.; Andrady, A.; Reisser, J. River plastic emissions to the world's oceans. Nat. Commun. 2017, 8, 15611. [CrossRef] [PubMed]

5. Van Emmerik, T.; Schwarz, A. Plastic debris in rivers. Wiley Interdiscip. Rev. Water 2020, 7, e1398. [CrossRef]

6. Jambeck, J.R.; Geyer, R.; Wilcox, C.; Siegler, T.R.; Perryman, M.; Andrady, A.; Narayan, R.; Law, K.L. Plastic waste inputs from land into the ocean. Science 2015, 347, 768-771. [CrossRef] [PubMed]

7. Mattsson, K.; Hansson, L.-A.; Cedervall, T. Nano-plastics in the aquatic environment. Environ. Sci. Process. Impacts 2015, 17, 1712-1721. [CrossRef] [PubMed]

8. Baier, D.; Rausch, T.M.; Wagner, T.F. The Drivers of Sustainable Apparel and Sportswear Consumption: A Segmented Kano Perspective. Sustainability 2020, 12, 2788. [CrossRef]

9. Poonyakan, A.; Rachakornkij, M.; Wecharatana, M.; Smittakorn, W. Potential Use of Plastic Wastes for Low Thermal Conductivity Concrete. Materials 2018, 11, 1938. [CrossRef] 
10. Geyer, R.; Jambeck, J.R.; Law, K.L. Production, use, and fate of all plastics ever made. Sci. Adv. 2017, 3, e1700782. [CrossRef]

11. Sistem Informasi Pengelolaan Sampah Nasional. Available online: http:/ / sipsn.menlhk.go.id/?q=3a-komposisi-sampah (accessed on 4 August 2020).

12. Godfrey, L. Waste Plastic, the Challenge Facing Developing Countries-Ban It, Change It, Collect It? Recycling 2019, 4, 3. [CrossRef]

13. Nurdiana, J.; Franco-García, M.-L.; Hophmayer-Tokich, S. Incorporating circular sustainability principles in DKI. Jakarta: Lessons learned from Dutch business schools management. In Towards Zero Waste; Franco-García, M.L., Carpio-Aguilar, J., Bressers, H., Eds.; Greening of Industry Networks Studies; Springer: Cham, Switzerland, 2019; Volume 6, pp. 145-163.

14. Napper, I.E.; Thompson, R.C. Plastic Debris in the Marine Environment: History and Future Challenges. Glob. Chall. 2020, 4, 1900081. [CrossRef]

15. EMF (The Ellen Mac Arthur Foundation). Urban Biocycles. 2017. Available online: https:/ /www.ellenmacarthurfoundation.org/ publications/urban-biocyles (accessed on 20 June 2020).

16. Jain, A.; Siddique, S.; Gupta, T.; Jain, S.; Sharma, R.K.; Chaudhary, S. Fresh, Strength, Durability and Microstructural Properties of Shredded Waste Plastic Concrete. Iran. J. Sci. Technol. Trans. Civ. Eng. 2019, 43, 455-465. [CrossRef]

17. Kaufmann, J.; Frech, K.; Schuetz, P.; Münch, B. Rebound and orientation of fibers in wet sprayed concrete applications. Constr. Build. Mater. 2013, 49, 15-22. [CrossRef]

18. Alani, A.M.; Beckett, D. Mechanical properties of a large scale synthetic fibre reinforced concrete ground slab. Constr. Build. Mater. 2013, 41, 335-344. [CrossRef]

19. Babafemi, A.J.; Šavija, B.; Paul, S.C.; Anggraini, V. Engineering Properties of Concrete with Waste Recycled Plastic: A Review. Sustainability 2018, 10, 3875. [CrossRef]

20. Islam, J.; Meherier, S.; Islam, A.R. Effects of waste PET as coarse aggregate on the fresh and harden properties of concrete. Constr. Build. Mater. 2016, 125, 946-951. [CrossRef]

21. Batayneh, M.; Marie, I.; Asi, I. Use of selected waste materials in concrete mixes. Waste Manag. 2007, 27, 1870-1876. [CrossRef]

22. Akinpelu, M.A.; Odeyemi, S.O.; Olafusi, O.S.; Muhammed, F.Z. Evaluation of splitting tensile and compressive strength relationship of self-compacting concrete. J. King Saud Univ.-Eng. Sci. 2019, 31, 19-25. [CrossRef]

23. Lavanya, G.; Jegan, J. Evaluation of relationship between split tensile strength and compressive strength for geopolymer concrete of varying grades and molarity. Int. J. Appl. Eng. Res. 2015, 10, 35523-35529.

24. Choi, Y.; Yuan, R.L. Experimental relationship between splitting tensile strength and compressive strength of GFRC and PFRC. Cem. Concr. Res. 2005, 35, 1587-1591. [CrossRef]

25. Kim, S.B.; Yi, N.H.; Kim, H.Y.; Kim, J.-H.J.; Song, Y.-C. Material and structural performance evaluation of recycled PET fiber reinforced concrete. Cem. Concr. Compos. 2010, 32, 232-240. [CrossRef]

26. Nikbin, I.M.; Rahimi, S.; Allahyari, H.; Fallah, F. Feasibility study of waste Poly Ethylene Terephthalate (PET) particles as aggregate replacement for acid erosion of sustainable structural normal and lightweight concrete. J. Clean. Prod. 2016, 126, 108-117. [CrossRef]

27. Silva, A.L.P.; Prata, J.C.; Walker, T.R.; Campos, D.; Duarte, A.C.; Soares, A.M.; Barcelò, D.; Rocha-Santos, T. Rethinking and optimising plastic waste management under COVID-19 pandemic: Policy solutions based on redesign and reduction of single-use plastics and personal protective equipment. Sci. Total Environ. 2020, 742, 140565. [CrossRef] [PubMed]

28. Bahij, S.; Omary, S.; Feugeas, F.; Faqiri, A. Fresh and hardened properties of concrete containing different forms of plastic waste-A review. Waste Manag. 2020, 113, 157-175. [CrossRef] [PubMed]

29. Fraternali, F.; Ciancia, V.; Chechile, R.; Rizzano, G.; Feo, L.; Incarnato, L. Experimental study of the thermo-mechanical properties of recycled PET fiber-reinforced concrete. Compos. Struct. 2011, 93, 2368-2374. [CrossRef]

30. Merli, R.; Preziosi, M.; Acampora, A.; Lucchetti, M.C.; Petrucci, E. Recycled fibers in reinforced concrete: A systematic literature review. J. Clean. Prod. 2020, 248, 119207. [CrossRef]

31. Pešić, N.; Živanović, S.; Garcia, R.; Papastergiou, P. Mechanical properties of concrete reinforced with recycled HDPE plastic fibres. Constr. Build. Mater. 2016, 115, 362-370. [CrossRef]

32. Lopez, N.; Collado, E.; Diacos, L.A.; Morente, H.D. Evaluation of Pervious Concrete Utilizing Recycled HDPE as Partial Replacement of Coarse Aggregate with Acrylic as Additive. MATEC Web Conf. 2019, 258, 01018. [CrossRef]

33. ASTM C 33-99ae1. Standard Specification for Concrete Aggregates; ASTM International: West Conshohocken, PA, USA, 2002.

34. ASTM International. Standard Test Method for Bulk Density ("Unit Weight") and Voids in Aggregate; ASTM C29/C29M-07: West Conshohocken, PA, USA, 2003.

35. ASTM International. Standard Test Method for Resistance to Degradation of Small-Size Coarse Aggregate by Abrasion and Impact in the Los Angeles Machine; ASTM C131/C131M-20: West Conshohocken, PA, USA, 2005.

36. American Concrete Institute. ACI Manual of Concrete Practice. In Part 1: Materials and General Properties of Concrete; American Concrete Institute: Farmington Hills, MI, USA, 2000.

37. Setareh, M.; Darvas, R. Reinforced Concrete Technology. In Concrete Structures; Springer: Cham, Switzerland, 2017 ; pp. 1-35. [CrossRef]

38. ASTM International. Standard Test Method for Slump of Hydraulic Cement Concrete; ASTMC143: West Conshohocken, PA, USA, 2000.

39. ASTM International. Test Method for Compressive Strength of Cylindrical Concrete Specimens; ASTMC39: West Conshohocken, PA, USA, 2014. 
40. ASTM International. Standard Test Method for Splitting Tensile Strength of Cylindrical Concrete Specimens; ASTMC496: West Conshohocken, PA, USA, 2009.

41. Hasan, M.J.; Afroz, M.; Mahmud, H.M.I. An experimental investigation on the mechanical behavior of macro synthetic fibre reinforced concrete. Int. J. Civ. Environ. Eng. 2011, 11, 18-23.

42. Xu, L.; Li, B.; Ding, X.; Chi, Y.; Li, C.; Huang, B.; Shi, Y. Experimental Investigation on Damage Behavior of Polypropylene Fiber Reinforced Concrete under Compression. Int. J. Concr. Struct. Mater. 2018, 12, 68. [CrossRef]

43. Turner, R.P.; Kelly, C.A.; Fox, R.; Hopkins, B. Re-Formative Polymer Composites from Plastic Waste: Novel Infrastructural Product Application. Recycling 2018, 3, 54. [CrossRef]

44. Kamaruddin, M.A.; Abdullah, M.M.; Zawawi, M.H.; Zainol, M.R.R. Potential use of Plastic Waste as Construction Materials: Recent Progress and Future Prospect. IOP Conf. Series Mater. Sci. Eng. 2017, 267, 012011. [CrossRef]

45. Mazaheripour, H.; Ghanbarpour, S.; Mirmoradi, S.; Hosseinpour, I. The effect of polypropylene fibers on the properties of fresh and hardened lightweight self-compacting concrete. Constr. Build. Mater. 2011, 25, 351-358. [CrossRef]

46. Yin, S.; Tuladhar, R.; Shi, F.; Combe, M.; Collister, T.; Sivakugan, N. Use of macro plastic fibres in concrete: A review. Constr. Build. Mater. 2015, 93, 180-188. [CrossRef]

47. Aldahdooh, M.; Jamrah, A.; Alnuaimi, A.; Martini, M.; Ahmed, M. Influence of various plastics-waste aggregates on properties of normal concrete. J. Build. Eng. 2018, 17, 13-22. [CrossRef]

48. Ismail, Z.Z.; Al-Hashmi, E.A. Use of waste plastic in concrete mixture as aggregate replacement. Waste Manag. 2008, 28 , 2041-2047. [CrossRef] [PubMed]

49. Albano, C.; Camacho, N.; Hernández, M.; Matheus, A.; Gutiérrez, A. Influence of content and particle size of waste pet bottles on concrete behavior at different $\mathrm{w} / \mathrm{c}$ ratios. Waste Manag. 2009, 29, 2707-2716. [CrossRef] [PubMed]

50. Almeshal, I.; Tayeh, B.A.; Alyousef, R.; Alabduljabbar, H.; Mohamed, A.M. Eco-friendly concrete containing recycled plastic as partial replacement for sand. J. Mater. Res. Technol. 2020, 9, 4631-4643. [CrossRef]

51. Tasdemir, C.; Sengul, O.; Tasdemir, M.A. A comparative study on the thermal conductivities and mechanical properties of lightweight concretes. Energy Build. 2017, 151, 469-475. [CrossRef]

52. Alqahtani, F.K.; Ghataora, G.; Khan, M.I.; Dirar, S. Novel lightweight concrete containing manufactured plastic aggregate. Constr. Build. Mater. 2017, 148, 386-397. [CrossRef]

53. Mohammed, A.A.; Mohammed, I.I.; Mohammed, S.A. Some properties of concrete with plastic aggregate derived from shredded PVC sheets. Constr. Build. Mater. 2019, 201, 232-245. [CrossRef]

54. Awad, H.K. Influence of Cooling Methods on the Behavior of Reactive Powder Concrete Exposed to Fire Flame Effect. Fibers 2020, 8, 19. [CrossRef]

55. Neville, A.M. Properties of Concrete, 4th ed.; Longman Group: Essex, UK, 1995; p. 844. 